ship and control quickly brought an end to that practice. An electronic version is under consideration but its lack of the personal touch is a major concern. It seems unlikely, in any case, that an electronic version could ever have the attraction, charm, and visibility of the original. Ms. Pittman, like Ms. Osborne, suggests that through this approach to answering reference questions "Staff members ... can add a touch of geniality or humor in their manner of answering."

\title{
Using a DBMS to maintain a reserve reading collection
}

\section{By Gregory A. Crawford}

\author{
Reference and Public Services Librarian \\ Moravian College
}

One of the most heavily used collections in Reeves Library at Moravian College is the reserve reading collection. This collection contains photocopies of articles, books, videotapes, slide/tape presentations, computer software, and cassette tapes for language instruction. This article will discuss the results of using a microcomputer-based database management system to maintain a reserve reading collection. The system discussed was used for a period of two years until being rep]aced by the Dynix reserve book room software module.

Since the collection continually grew and was constantly in a state of change, it quickly outgrew the manual system by which it was maintained. The first step in automating the collection was taken by the librarian in charge of circulation. She studied how other local colleges and universities handled their reserve collections and ultimately modeled her system on that in use at Lehigh University.

In the collection, each item was given a unique number. Books used in college courses received a plain number (e.g., 96), books used in seminary courses were indicated by an " $\mathrm{S}$ " preceding the number (e.g., S-96), and photocopied materials received a number preceded by "P" (e.g., P-96). All items were also color-coded to indicate their circulation status: orange bands indicated a two-hour circulation period, while yellow bands showed that the item may leave the library for an instructorspecified length of time which varied from overnight to seven days.

Students were hired to develop and maintain a database for this collection, thus becoming the first step toward automation in the library. Various students over a span of several years used a Unix editor to create records for the items on reserve. These were ASCII text files which used hard tabs to indicate individual fields. The students a]so wrote and continually enhanced a Pascal program that sorted the records into various lists that could then be printed on demand. Three major printouts were run, each preceded by the appropriate sort algorithm: MASTRES, a complete listing of all items in the reserve collection; a list of items that were on reserve for classes taught in the current semester, called FALLRES, SPRGRES, and SUMRES to distinguish the semester; and NUMRES, a shelflist consisting of all items currently on reserve by their assigned numbers.

The system worked well, although the students who controlled the system varied considerably in their attention to details and depth of understanding of the reserves collection. Thus, the staff spent considerable time in comparing the printouts to the reserves worksheets and in proofreading them to clean up errors and inconsistencies.

Then one day the computer center announced to the library that the minicomputer on which the reserves system resided was going to be disconnected. This necessitated that we find another method to control the collection, preferably one that did not revert to a card-based system. Since the Reference and Public Services Department had recently been given a computer for use in word processing and database searching, a microcomputer-based system seemed logical. A simple, userfriendly database management program was sought out. Since the library had no funds with which to purchase one of the more expensive database management software packages, shareware was investigated and we decided to try PC-File III, produced by ButtonWare, Inc. After examining the software and designing a few trial databases, we purchased a registered copy of the software and went to the next phase of the project, i.e., transferring our records off the minicomputer to a floppy 


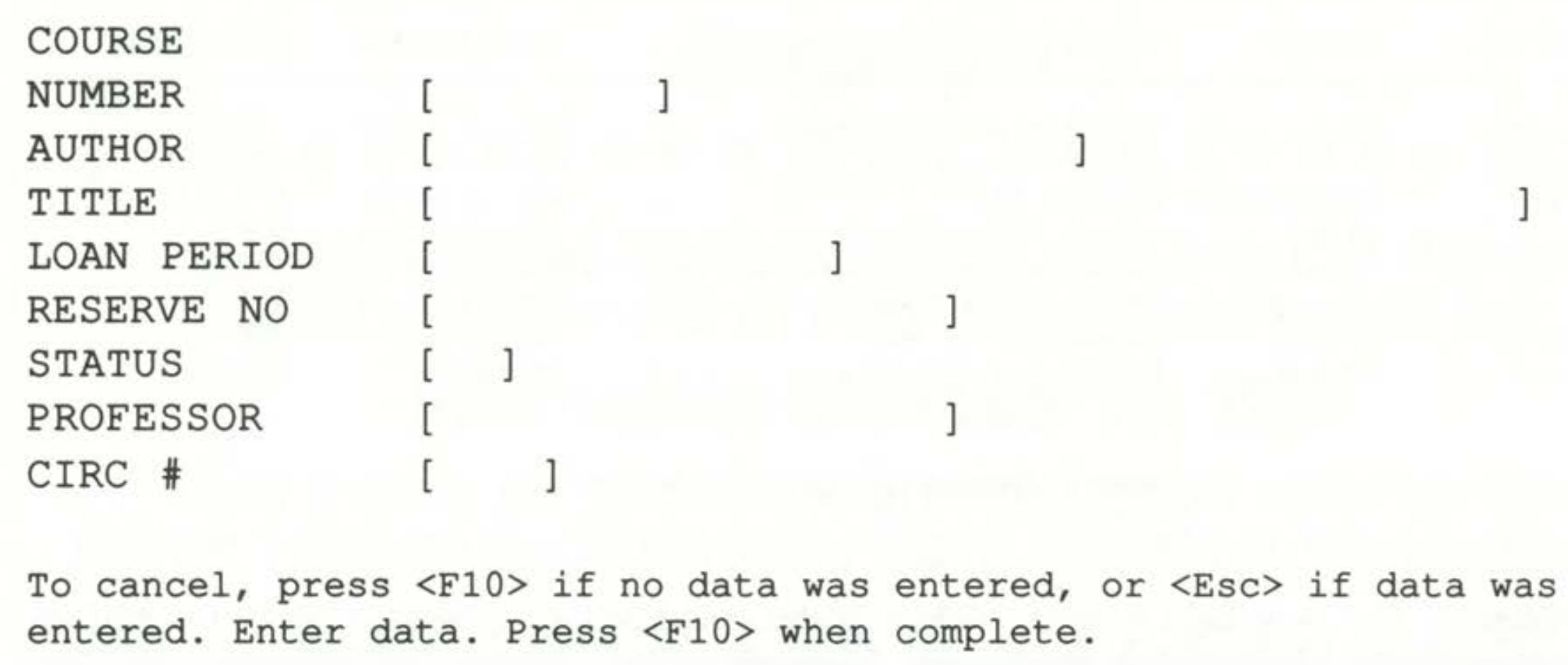

Figure 1. Database template.

disk that would form the basis of the reserve database.

The entire reserve readings collection already existed in machine-readable form and represented hundreds of hours of work. We did not want to have to rekey this information back into a computer. Thus, it seemed advantageous to try downloading the records. As designed by the students, the structure of the file was not very flexible, with each record contained in a line of data and fields indicated by hard tabs.

Transferring the records into a new database would permit us to add fields that could greatly enhance the overall functioning of the database. Specific fields slated for addition included professor, status of the item, and circulation count. Using a DBMS would also permit easier handling of various reports used during the year to keep the collection up to date and allow special reports to be generated at any time. In addition, since the database would be maintained on a microcomputer using a DOS version of PC-File III, it would be transportable over a variety of computers. Furthermore, updating of records was not limited to times when the computing facilities were available, but could be done whenever our work-study students could fit it into their schedules.

Since the database was beginning with over a thousand records containing data elements in a specific order that had proven useful over time, the design of the database template was somewhat restricted (Figure 1). Thus the same field order had to be used and appropriate names given to each field. Since the original file used specific tab settings to delineate fields, we knew the existing default maximum length of each field. Although entered as straight text using an editor, each field had a definite meaning that was used as the name for the database field names. The field names included department, course number, author, title, loan period, and reserve number. New fields could be added most easily, and most logically, at the end of the record. We added the fields for status of the item (i.e., on or off the current reserve list), professor, and circulation total. An edit mask was placed on the circulation field which permitted the input of positive numerical values only.

Downloading the file presented several challenges. In the initial attempts, the communications program (Smartcom II) and the telephone hookup caused crashes so that only part of the file was successfully downloaded. Perseverance paid off and finally the downloading technique was mastered. The first successful attempt downloaded the file in a formatted mode, filling in the fields up to the tab settings with spaces. This proved unworkable because the students who input the data often paid no strict attention to these settings and allowed fields to run over the specified tabs. As the students had designed it, the Pascal program treated each record merely as a formatted line that permitted overriding the tab-specified field lengths and not as a record containing individual fields. Since the goal of their programming efforts was to produce printouts that always printed data in the same order and not to manipulate the records individually, little thought went into designing specific field lengths. When we attempted to import this formatted file into PC-File III records with a field length that exceeded the tab, mayhem ensued.

A second download of the file as an unformatted ASCII file worked beautifully. This method used the character string "->" to signify a tab in the Unix file. Next, WordStar was used to change the string "->" automatically to a comma by using the find and replace command, which resulted in a file that could easily be imported into PC-File III because it resembled a mail-merge file. Because the data had been automatically edited to shape it into a 


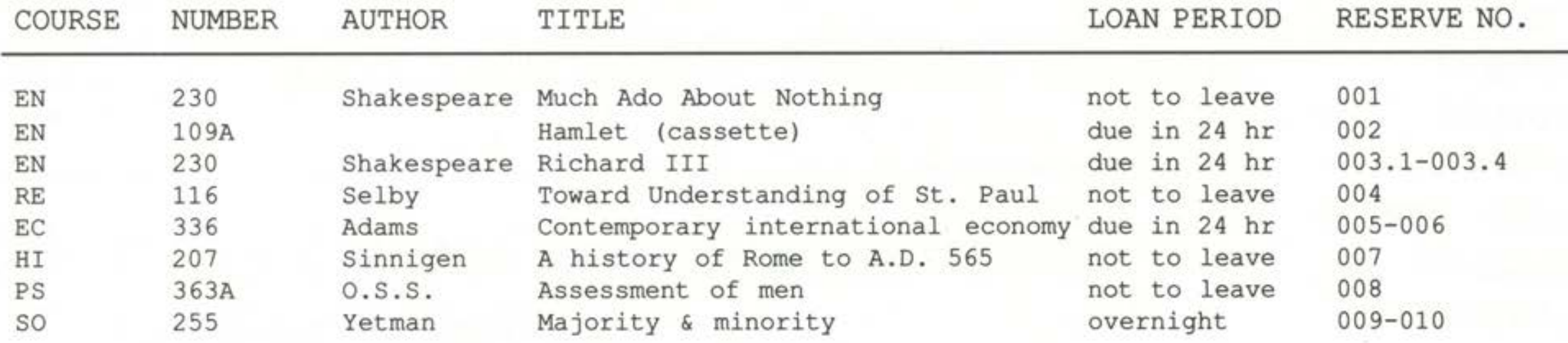

Figure 2. Portion of a sorted printout.

comma delineated file, new field lengths could easily be assigned within the template to improve the size and usefulness of the fields. The major restriction was the page width of our printer, since printed reports were the main products of the database.

Problems arose when the records were sorted into shelflist order using the reserve number field. Since the reserve numbers often included alphabetic characters, the sorting algorithm could not put the items into a proper numeric sequence. Thus, the sort resulted in a list such as $\mathrm{P}-1, \mathrm{P}-10, \mathrm{P}$ $100, \mathrm{P}-2, \mathrm{P}-20, \mathrm{P}-200$, etc. In a manual operation, WordStar was used again to search for the string "P." and the field was edited to its appropriate number, P-1 became P-0001, P100 became P0100 , etc. All the records had to be examined to ensure that the sorting would be correct (Figure 2).

Many benefits arose out of using PC-File III. Maintaining the data became much easier. Modifications to the records, such as correcting misspellings, could be done very quickly. When the registrar's office began using new two-letter codes for departments, the changes were easily handled by the global update feature of the software.

Additionally, letters to instructors, previously a laborious task, were generated by sorting the database by professor and then saving the resulting report to a floppy disk. WordStar was then used to generate a form letter to each professor who had reserve readings currently being used. The professors would then indicate on the letter which items were to be removed and which were to be retained on reserve for future use. If all readings for a course were being removed, the global delete function of PC-File III would quickly delete all the relevant records from the database.

To assist the students who maintained the database, a detailed manual was written. This manual discussed each phase of the reserve process: adding, modifying, and deleting items; generating reports; and printing letters to professors.

New versions of PC-File III, especially PCFile+, were excellent. Since the database and tem- plates could be carried over between the various versions of the software, implementation of the newer versions was simple. The sorting routines in the newer versions were much quicker. All the report forms, however, needed to be redone since new options and commands were available in PCFile+. We skirted this issue by using PC-File+ for the routine maintenance of the database and for sorting and by using PC-File III for the printing of reports.

The use of PC-File III and PC-File+ gave us much needed flexibility in maintaining our reserve reading collection. Both were simple to operate and easy to teach to students. Better control of the collection resulted and many hours of time were saved. The inexpensive price of the software definitely warrants its use and Jim Button of ButtonWare should be commended.

\section{ARL redesigns newsletter}

\section{ARL: A Bimonthly Newsletter of Research}

Library Issues and Actions is the redesigned and expanded newsletter of the Association of Research Libraries. It covers not only information about current ARL publications and programs, but reporting and analysis of trends and concerns relevant to research libraries and their place within the world of higher education, government policy, and technology.

The July 4, 1990, issue featured articles on "Scholarly Publishing in the NREN" and "Federal Information in an Age of Electronic Communication." Additional sections cover legislative matters, training, and publications offered by the ARL Office of Management Services, and news about ARL members and projects.

The newsletter is edited by C. Brigid Welch, ARL/OMS, 1527 New Hampshire Ave., N.W., Washington, DC 20036. Non-ARL members may subscribe for $\$ 40.00$ per year (six issues). 


\title{
Discounts of \\ $25 \% \bullet \bullet \bullet \bullet \bullet \bullet 35 \% \bullet \bullet \bullet \bullet \bullet \bullet 50 \%$
}

Just a short time left to take advantage of the American Chemical

Society's discount offer on microfilm purchases over $\$ 5,000$.

\section{Offer expires December 15, 1990}

Every primary journal and special publication on microfilm from Volume 1 through the 1988 volume year is available on this special offer.

\section{$25 \% \bullet \bullet \bullet \bullet \bullet \bullet-35 \% \bullet \bullet \bullet \bullet \bullet \bullet \cdot 50 \%$}

\section{Call today for a brochure to see if you qualify, or if you need a microforms catalog.}

\author{
Langmuir \\ Biochemistry
}

Organometallics

Macromolecules

Inorganic Chemistry

Journal of Medicinal Chemistry

Accounts of Chemical Research

The Journal of Organic Chemistry

Environmental Science \& Technology

Journal of Chemical and Engineering Data

Journal of Agricultural and Food Chemistry

ACS Division of Fuel Chemistry Preprints of Papers

Industrial and Engineering Chemistry Fundamentals

ACS Division of Petroleum Chemistry Preprints of Papers

Industrial and Engineering Chemistry Process Design and Development Industrial and Engineering Chemistry Product Research and Development Journal of Chemical Information and Computer Sciences

Industrial and Engineering Chemistry Research Journal of the American Chemical Society

Industrial and Engineering Chemistry

The Journal of Physical Chemistry

Chemical Research in Toxicology

Chemical and Engineering News

Analytical Chemistry

Chemical Reviews

Energy \& Fuels

CHEMTECH

SciQuest

American Chemical Society, Microforms Program, 1155 Sixteenth Street, N.W., Washington D.C. 20036 202-872-4376 